\title{
Spatial characteristics of avalanche activity in an Alpine valley - a GIS approach
}

\author{
Andreas Stoffel, Roland Meister, Jürg Schweizer \\ Swiss Federal Institute for Snow and Avalanche Research, CH-7260 Davos Dorf, Switzerland
}

\begin{abstract}
A dataset of daily avalanche activity observed consistently for 14 years in the surroundings of Zuoz in the Engadine valley (eastern Swiss Alps) is analyzed. All medium-sized and larger avalanches had been mapped by the local snow and avalanche observer. They were digitized into a geographic information system (GIS) and linked to the daily snow and avalanche observations. Thus the avalanche activity and its spatial distribution could be analyzed and visualized. A classification for avalanche size and avalanche activity is proposed. In $52 \%$ of the potential starting zones an avalanche is released at least once in 14 years. The avalanche area decreases strongly with the frequency of avalanche occurrence. Preliminary analysis of the relation of daily avalanche activity to weather, snow and snow cover revealed a wide variety of contributory factors. Even for large amounts of new snow, snow-cover conditions prior to snowfall or temperature evolution might decide the extent of the avalanche activity. For six examples, the avalanche hazard (five degree European scale) is visualized by means of avalanche activity. The GIS approach will be followed to build a tool for local avalanche forecasting in Zuoz.
\end{abstract}

\section{INTRODUCTION}

Spatial representation of avalanche activity - potential and observed - is crucial for local avalanche forecasting. It answers some of the key questions: where and how often do avalanches occur, of what size and under what conditions? A unique data set (14 years) of detailed mapping of avalanche occurrence in the surroundings of the village of $\mathrm{ZuOz}$ (1716 m a.s.l.) in the Engadine valley (eastern Swiss Alps) forms the base of the study (Fig. 1). Zuoz may be considered to have a continental climate (mean winter air temperature $-8^{\circ} \mathrm{C}$, mean winter precipitation $270 \mathrm{~mm}$ ). The observed avalanche activity was characterized by using a geographic information system (GIS) (ARC/INFO). To measure avalanche activity, the area covered by avalanches was considered. The relation to weather, snow and snow-cover conditions has, to date, only been analyzed preliminarily. The final aim is to use avalanche activity together with weather, snow and snow-cover data as the knowledge-base for a local forecasting tool. A GIS application, linking snow and weather data with avalanche activity, has already been developed. It will be used to visualize the output of the knowledge-based system. Snow-cover information from snow profiles will be used as an input as proposed by Schweizer and Föhn (1996).

\section{DATABASE}

Since the winter of 1982-83, the local snow and avalanche observer at Zuoz has mapped meticulously avalanche activity in the surroundings of the village. Generally, he did not consider small avalanche situations. At the same time, he characterized all situations (including the small ones) according to the Swiss observation guidelines (Table 1). Typically, the number of occurrences (or frequency) of a specific avalanche situation strongly decreases with the increasing number and size of avalanches during the situation. In the 14 years (until 1995-96), he observed and mapped about 1100 avalanches on 150 days. The dataset includes naturally and artificially triggered avalanches. The two main avalanche paths that threaten the village are controlled by mortar fire (Fig. 2; insets A and B). In addition, the conventional daily snow and weather observation from a study plot at Zuoz is available including: new-snow depth, snow depth, weather type and intensity, wind direction and speed, air and snow temperature, snow-surface condition, ram-penetration depth and water equivalent of new snow. Bimonthly, snow profiles have also been taken.

Table 1. Avalanche observation and its encoding according to the Swiss observational guidelines: number, size and damage. For the 14year period 1982-83 to 1995-96 (2118 days, December-April) the frequency of occurrence is given as observed at Zuoz

Encoding Damage, number and size $\quad \begin{gathered}\text { Frequey of } \\ \text { occurrence }\end{gathered}$

$\begin{array}{lc}\text { Observation impossible } & 324 \\ \text { No avalanches } & 1589 \\ \text { Unknown size } & 0 \\ \text { Fatalities } & 0 \\ \text { Involvements } & 0 \\ \text { Property damage } & 1 \\ \text { Several }(>2) \text { large avalanches } & 6 \\ \text { Some }(1 \text { to 2) large avalanches } & 9 \\ \text { Several medium avalanches } & 22 \\ \text { Some medium avalanches } & 49 \\ \text { Some or several small avalanches } & 118\end{array}$




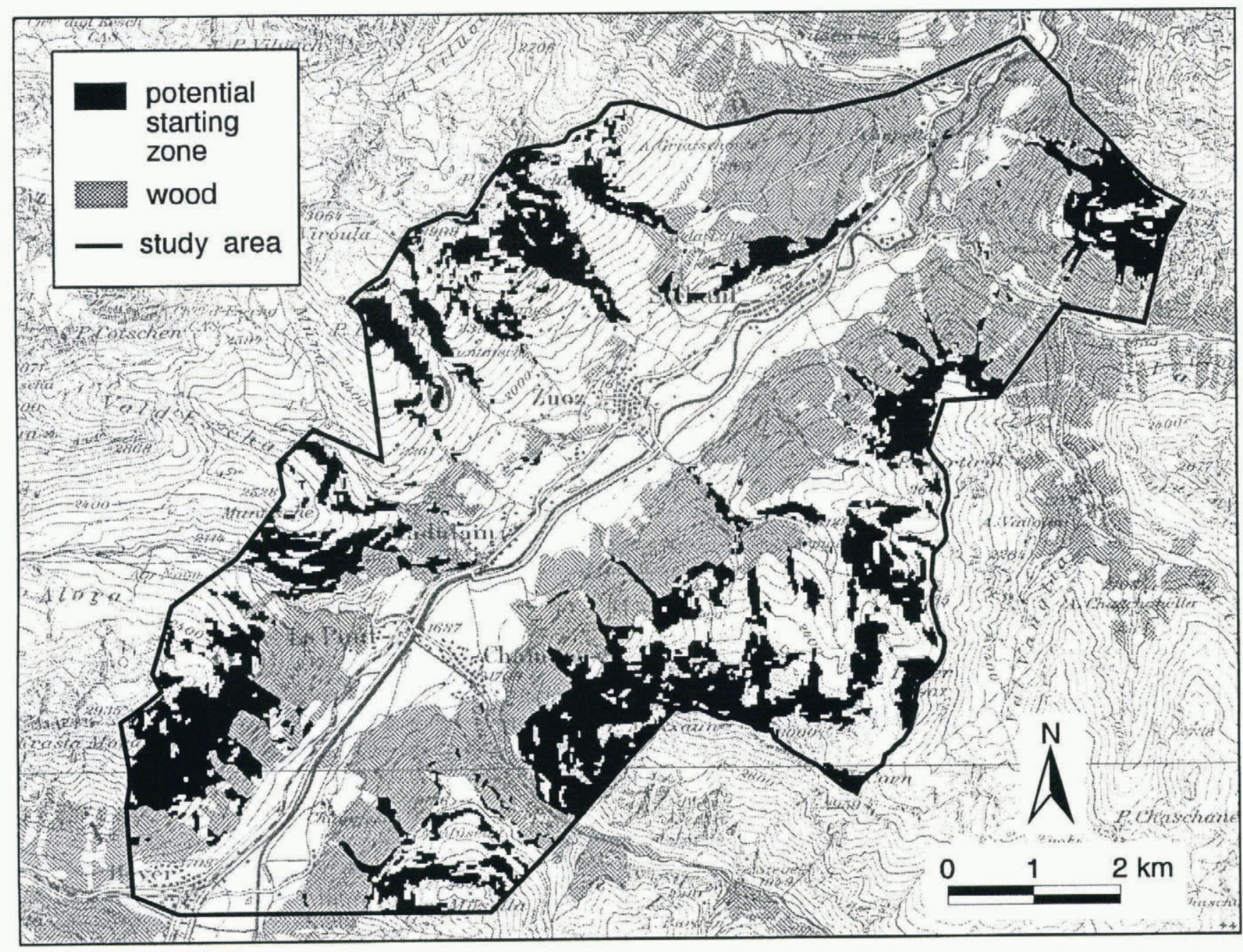

Fig. 1. Study area around Zuoz in Engadine valley (Swiss Alps) with calculated potential avalanche starting zones. Digital map

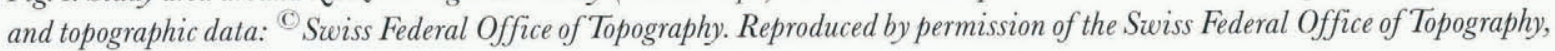
20 June 1997.

All avalanches have been digitized from the original transparency drawings, have been checked for plausibility and linked to the imported snow and weather observations to build the GIS system. Thus, the avalanche activity can be analyzed and visualized. To ensure observational consistency, the study area was reduced to a region visible from the village and the main road in the valley floor, covering $71 \mathrm{~km}^{2}$ (Fig. 1). It includes the Inn valley, between Bever and Chapella, and the adjacent slopes. As the valley runs from southwest to northeast, slopes of the southeasterly and northwesterly aspect (slope orientation) dominate. They cover $45 \%$ of the study area. The potential starting zone within the study area is approximately $14.6 \mathrm{~km}^{2}$ and was, as a first guess, calculated considering all slopes not wooded between $30^{\circ}$ and $50^{\circ}$ (Fig. 1). Terrain features, as ridges or gullies, have not been taken into account. The frequency of aspects in the potential starting zone is similar to that in the study area.

\section{AVALANCHE ACTIVITY}

As a measure of avalanche activity per day, the area covered by avalanches on that day is considered. This area therefore includes the starting zone, the track and the run-out zone. Of course, it would be more appropriate to use the avalanche volume but fracture height and size of starting zone org/10.3189/1998A0G26-1-329-336 Published online by Cambridge University Press is often unknown. However, as run-out distance strongly depends on fracture height, the volume might implicitly be included, at least partly.

The reduction to the study area defined above reduced the dataset to 858 avalanches on 137 days; thereof, 765 naturals, 40 triggered by mortar fire and 53 artificials by other triggers (animal, skier and snow cat).

For the 14 year observation period, all avalanches are represented in Figure 2 which shows the spatial frequency (or return period) of avalanche occurrence, i.e. where and how often avalanches did occur. The area hit at least once by an avalanche covers $14.7 \mathrm{~km}^{2}$ (and is in the following called the avalanche area). Thereof $7.6 \mathrm{~km}^{2}$ are within the calculated potential starting zone. In other words, $52 \%$ of the potential starting zone has avalanched at least once during the 14 year observation period. Schaer (1995) found values (which he called an avalanche-activity factor) between 20 and $40 \%$ for major events, depending on the return period (20-100 years). Figure 3 summarizes the spatial avalanche frequency given in Figure 2. The area covered by avalanches decreases strongly with frequency of avalanche occurrence. The area hit only once in 14 years is $43 \%$ of the total avalanche area. Only $1.3 \%$ of the avalanche area is covered by an avalanche at least once a year. The strong decrease in Figure 3 which may be described by an exponential function with negative exponent is known from other studies (Föhn, 


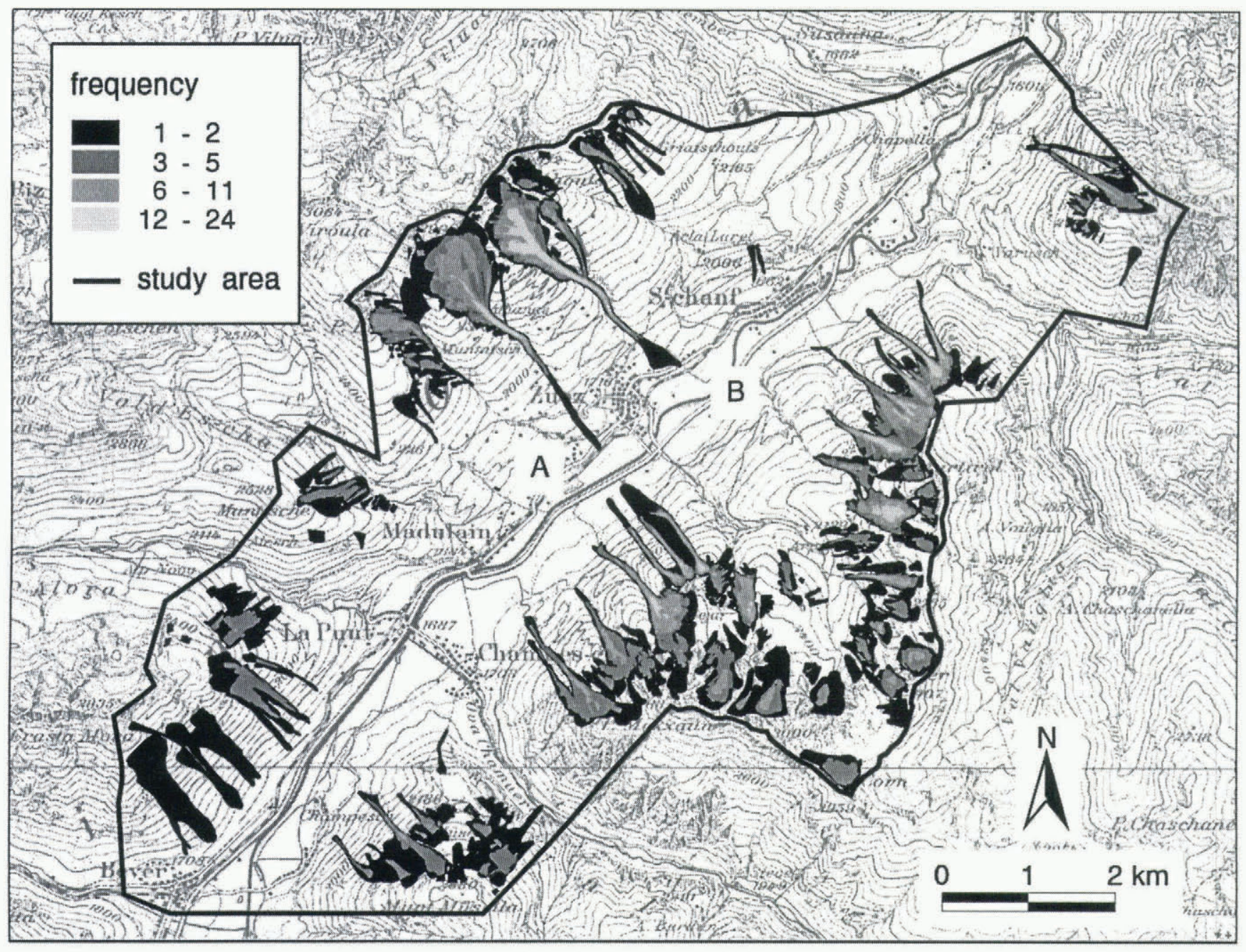

Fig. 2. Spatial distribution of frequency of avalanche occurrence over the 14 year period of avalanche observation. A and B denote the two avalanche paths that are frequently triggered by mortar fire. Digital map and topographic data: ${ }^{C}$ Swiss Federal Office of Topography. Reproduced by permission of the Swiss Federal Office of Topography, 20 June 1997.

1975; Föhn and Meister, 1982) and seems to be typical for frequency (or return period) and magnitude of natural hazards (Schweizer, 1995).

The frequency of aspects differs between the potential starting zone and the part of the observed avalanche area

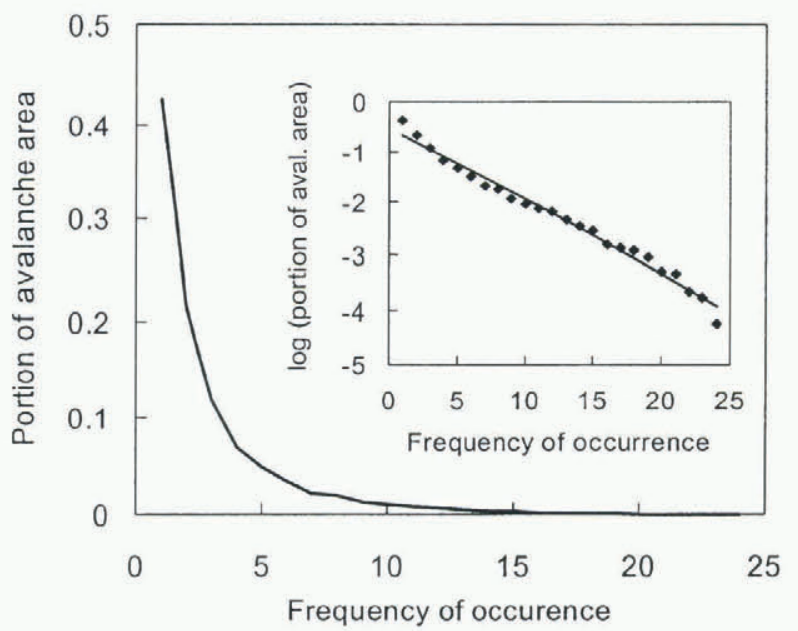

Fig. 3. Frequency of avalanche occurrence (in 14 years) per area related to the total avalanche area (i.e. the area that had been covered at least once by an avalanche during the 14 year period of observation ). that lies within the potential starting zone (Fig. 4). The southerly (more sunny) aspects are less frequently observed compared to the potential starting zones and vice versa for the northerly aspects. The difference in distribution is explained by generally different snow height and snow-cover stability in shady and sunny slopes.

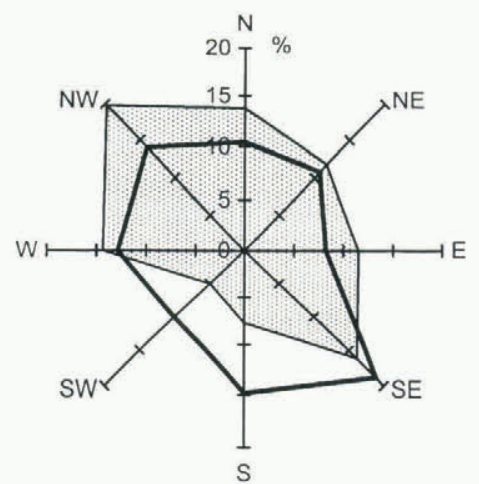

ㅁobserved avalanches (starting zones only)

口 potential starting zones

Fig. 4. Relative frequency of aspects of observed avalanches vs relative frequency of aspects in potential starting zones. 
Table 2. Avalanche-size classification based on area and frequency of occurrence at Zuoz observed during 14 years

\begin{tabular}{lcc}
\hline Avalanche size & $\begin{array}{c}\text { Area } \\
\mathrm{km}^{2}\end{array}$ & $\begin{array}{c}\text { Frequency of } \\
\text { occurrence }\end{array}$ \\
\hline Small & $<0.01$ & 44 \\
Medium & 0.01 to 0.049 & 444 \\
Large & 0.05 to 0.099 & 244 \\
Very large & $\geq 0.1$ & 33 \\
\hline
\end{tabular}

To characterize the avalanche activity, in addition to the area covered by avalanches, the recorded number of avalanches was considered to calculate the average avalanche size, again given as an area. As there exists no avalanche classification giving detailed quantitative classes in Switzerland, as is the case e.g. in Canada (McClung and Schaerer, 1993), a classification is proposed and the avalanches observed at Zuoz were classified accordingly (Table 2). The frequency of occurrence (Table 2), only natural avalanches are considered, shows that the observer did in general really not map small avalanches, since avalanche days with small avalanches are much more, namely most frequent, as can be seen in Table 1 where all events, including the small ones, are considered. Figure 5 clearly shows the large variation of avalanche activity considering number and size of avalanches. The same avalanche activity, given as area, may be the result of some very large, several large or many medium avalanches. Alternatively, Figure 5 also shows that a qualitative description as used, e.g. in Table 1, can also be appropriate. In addition to the presently used classification, we propose the following terms to be used: "many medium avalanches", "many large avalanches" and "a lot of large or several very large avalanches". Consequently, the avalanche area observed per day is classified and a corresponding qualitative description is given in Table 3 .

The more detailed classification is also a prerequisite to relate avalanche activity to snow and weather data. Of course, the spatial representation with a GIS is by far the best means of characterizing avalanche activity. Some examples are given below. However, quantitative values of

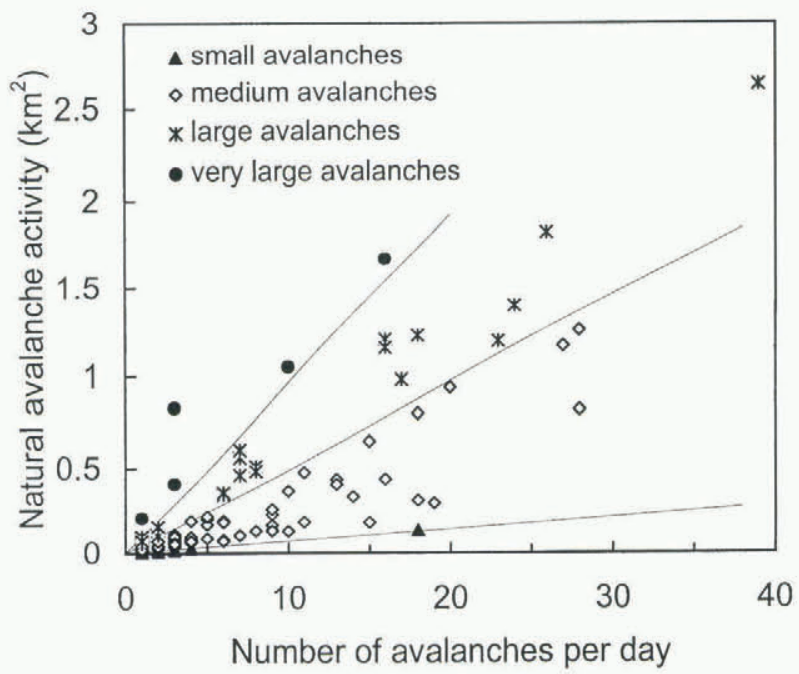

Fig. 5. Natural avalanche activity (given as area in $\mathrm{km}^{2}$ ) depending on the number and size of avalanches (sizes classes are given in Table 2).
Table 3. Classification of daily avalanche activity based on area, frequency of occurrence in the 14 year period and description based on number and size of avalanches

\begin{tabular}{lccl}
\hline $\begin{array}{l}\text { Avalanche } \\
\text { activity }\end{array}$ & $\begin{array}{c}\text { Area } \\
\mathrm{km}^{2}\end{array}$ & $\begin{array}{c}\text { Frequency of } \\
\text { occurrence }\end{array}$ & Number and size of avalanches \\
\hline Small & $<0.1$ & 56 & Some medium \\
Medium & 0.1 to 0.49 & 36 & Several medium or some large \\
Large & 0.5 to 0.99 & 9 & Many medium or several large \\
Very large & 1.0 to 1.49 & 8 & Many large or several very large \\
Extreme & $\geq 1.5$ & 3 & A lot of large or many very large \\
& & &
\end{tabular}

avalanche activity, as e.g. area or number and size of avalanches, are needed as the output variable for a future knowledge-based local forecasting tool.

\section{AVALANCHE ACTIVITY IN RELATION WEATHER, SNOW AND SNOW-COVER DATA}

TO

McClung and Tweedy (1993) have shown a possible approach for analyzing the factors that contribute to avalanche activity. Schneebeli and others (1997) proposed threshold values of $50 \mathrm{~cm}$ of snow depth for both the 3 day sum of new-snow depth and the total snow depth for large avalanches causing damage in the Inn valley. As a first step, we only preliminarily assess the 3 day sum of new-snow depth as an indicator for avalanching. Table 4 compares the frequency of the 3 day sum of new-snow depth of all days (potential) with the avalanche days (realization). Above about $20 \mathrm{~cm}$ of new snow there seems to be a fair likelihood of avalanche activity, but there exists small to medium activity for nearly any value of the new-snow depth below $50 \mathrm{~cm}$ (Fig. 6). The second largest avalanche activity (on 9 March 1991) was observed when the 3 day sum of new snow was zero. The situation was due to a distinct warming. The wide variety only decreases slightly if the snow depth prior to the snowfall period, 3 days before $\left(h s_{j-3}\right)$, is considered to take into account terrain roughness. However, excluding all days with $h s_{j-3} \leq 50 \mathrm{~cm}$ increases the probabilities for avalanch-

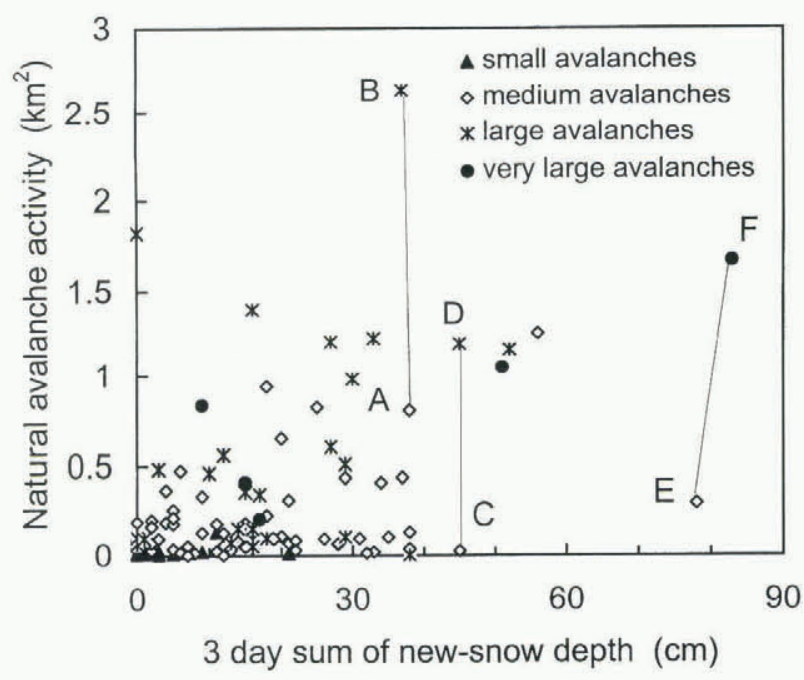

Fig. 6. Scatter plot of natural avalanche activity vs 3 day sum of new-snow depth including the according size of avalanches. Letters $A$ to $F$ indicate the six situations characterized in detail (Fig. 8; Table 5). 
Table 4. Frequency of occurrence of 3 day sum of new-snow depth ( $3 \mathrm{~d}$ shn) and probability for avalanches. Probability I is for all days, probability II considers only days with snow depth 3 days before $\left(h s_{\mathrm{j}-3}\right)$ larger than $50 \mathrm{~cm}$

\begin{tabular}{|c|c|c|c|c|c|c|}
\hline $\begin{array}{c}3 d \operatorname{shn} \\
\mathrm{cm}\end{array}$ & All days & Avalanche days & Probability I & $\begin{array}{c}\text { Days with } \\
h s_{\mathrm{j}-3}>50 \mathrm{~cm}\end{array}$ & $\begin{array}{c}\text { Avalanche days } \\
h s_{\mathrm{j}-3}>50 \mathrm{~cm}\end{array}$ & $\begin{array}{c}\text { Probability II } \\
h s_{\mathrm{j}-3}>50 \mathrm{~cm}\end{array}$ \\
\hline 0 & 1915 & 16 & 0.008 & 334 & 4 & 0.012 \\
\hline $1-10$ & 893 & 41 & 0.046 & 266 & 12 & 0.045 \\
\hline $11-20$ & 226 & 35 & 0.155 & 57 & 13 & 0.228 \\
\hline $21-30$ & 68 & 19 & 0.279 & 14 & 6 & 0.429 \\
\hline $31-40$ & 38 & 13 & 0.342 & 21 & 10 & 0.476 \\
\hline $41-50$ & 8 & 3 & 0.375 & 4 & 2 & 0.5 \\
\hline $51-60$ & 8 & 6 & 0.75 & 1 & 1 & 1 \\
\hline $61-70$ & 3 & 0 & 0 & 0 & 0 & - \\
\hline $71-80$ & 3 & 2 & 0.667 & 0 & 0 & - \\
\hline $81-90$ & 1 & 1 & 1 & 0 & 0 & - \\
\hline
\end{tabular}

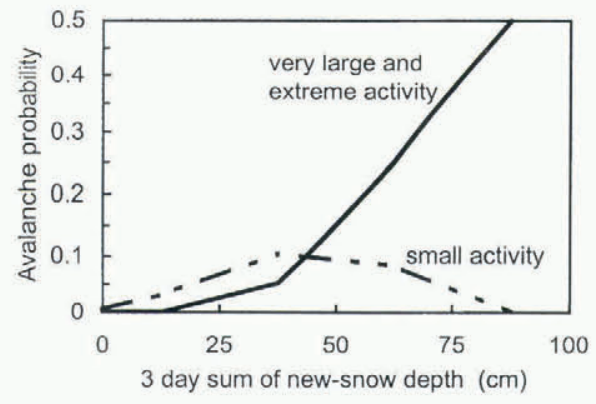

Fig. 7. Probability for small and very large/extreme avalanche activity depending on 3 day sum of new-snow depth (same data as in Figure 6). Classes used: <1, 1-25, 26-50, 51-75, $76-100 \mathrm{~cm}$.

ing by about $35 \%$ (Table 4). If the avalanche activity is split according to size (of activity) (Table 3), results become more indicative (Fig. 7). Small activity is found for small and medium amounts of the 3 day sum of new-snow depth; very large and extreme activity become more likely for values of the 3 day sum of new-snow depth larger than about $50 \mathrm{~cm}$.

In general, Figure 6 does not show a strong relation between the 3 day sum of new-snow depth and the natural avalanche activity. This might be due to the lack of other important factors such as wind, temperature and snow-cover conditions. In the following we describe three pairs of situations $(\mathrm{A}-\mathrm{F})$ with a similar 3 day sum of new-snow depth but very different avalanche activity (Fig. 6). The spatial distribution and extent of all six situations is shown in Figure 8. Weather, snow and snow-cover conditions are summarized in Table 5. All values given were measured at the Zuoz study plot. The snow-cover conditions are characterized only by means of the ram profile that is part of the bimonthly snow-cover observation. The type of ram profile is classified following the approach by de Quervain and Meister (1987) (Fig. 9). Profile type No. 1 is most frequent (about $30 \%$ ) in the study area, reflecting the continental type of climate. Intensive avalanche activity corresponds to profile types No. 5 and No. 7. Also given in Table 5 is the degree of avalanche hazard: low, moderate, considerable, high, very high (Meister, 1994), as estimated a posteriori based on avalanche activity. The avalanche hazard increases with increasing release probability, increasing extent of instabilities and increasing size of avalanches. Natural activity is unlikely for the low and moderate degrees. Therefore, the degree of hazard for the situations $\mathrm{A}$ to $\mathrm{F}$ is considerable or higher. The degree of very large is exclusively used for situations when large avalanches occur that reach the valley floor.

On 14 January 1986 (situation A in Figures 6 and 8) 21 medium avalanches were observed following a snowfall with a total of $38 \mathrm{~cm}$ of new snow. About 2 weeks later on 1 February 1986 (situation B in Figures 6 and 8) nearly the same amount of new snow resulted in 37 large avalanches. During the first snowfall period, air temperature rather favored stabilization of the new snow (slight increase from $-6^{\circ}$

Table 5. Characterization of the avalanche situations (Figs 6 and 8): 3 day sum of new-snow depth ( $3 d$ shn), air-temperature change during snowfall period ( $\Delta T$ ), average wind direction and speed, type of ram profile (see Fig. 9) and verified degree of avalanche hazard (using the European five-degree scale).

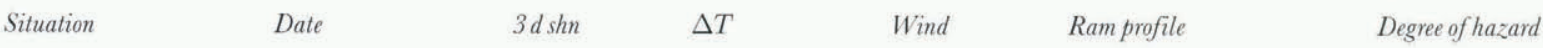

$\mathrm{cm} \quad{ }^{\circ} \mathrm{C}$

$\begin{array}{ccclll}\text { 14 Jan } 86 & 38 & +5 & \text { W, moderate } & 1 & \text { Considerable } \\ \text { 1 Feb } 86 & 37 & +11 & \text { SE, strong } & 1 & \text { High } \\ \text { 26 Feb } 89 & 45 & -4 & \text { S, strong } & 5 & \text { Moderate to considerable } \\ \text { 2 Mar 94 } & 45 & +7 & \text { S, moderate } & 7 & \text { Considerable to high } \\ \text { 23 Dec 91 } & 78 & -1 & \text { W, very strong } & 6 & \text { Considerable } \\ \text { 17 Jan 83 } & 83 & +12 & \text { NW, very strong } & 5 & \text { High to very high }\end{array}$




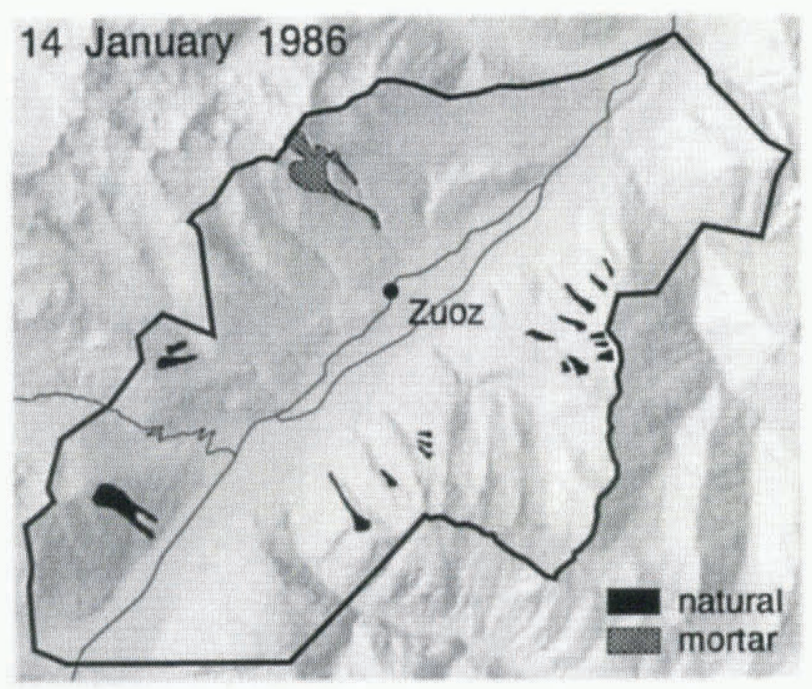

a

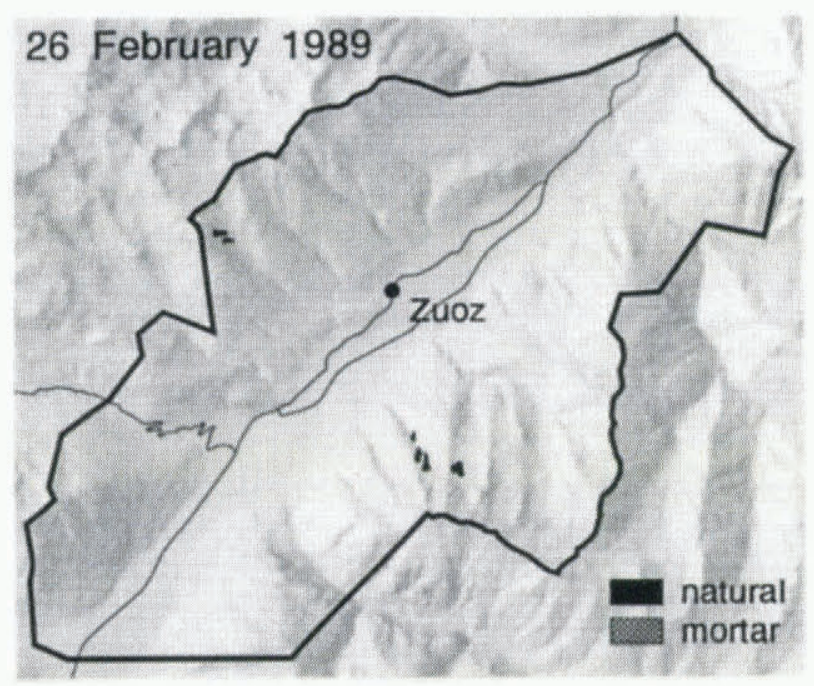

c

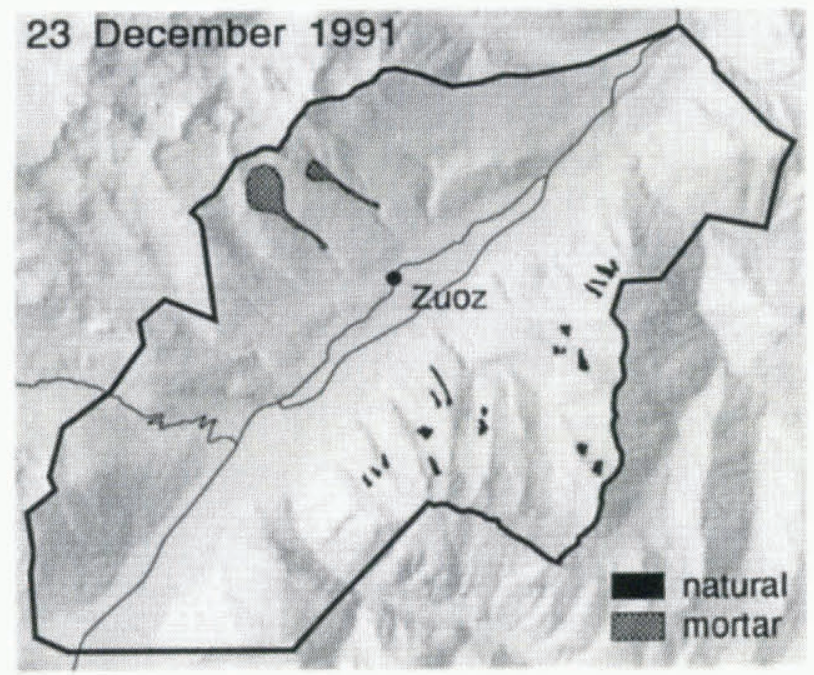

e

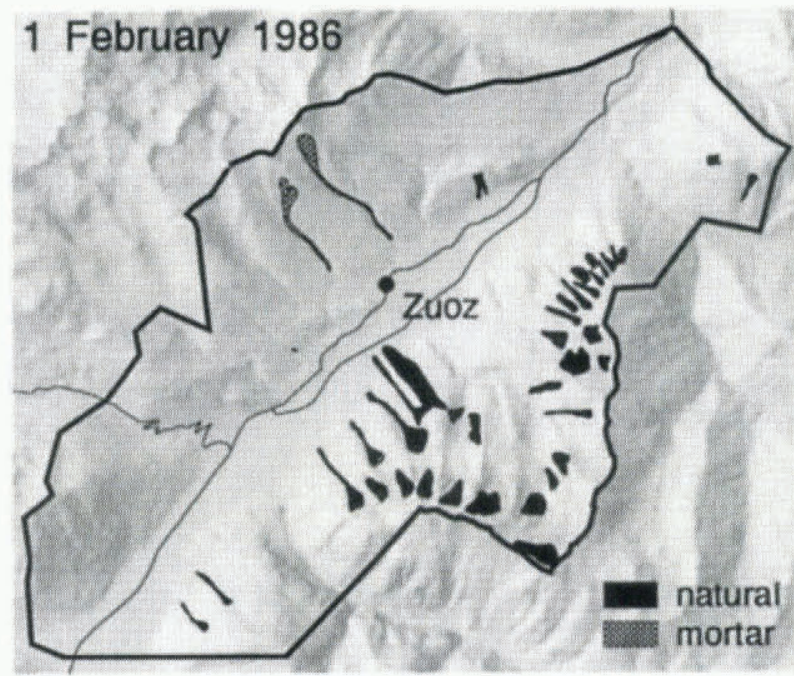

b

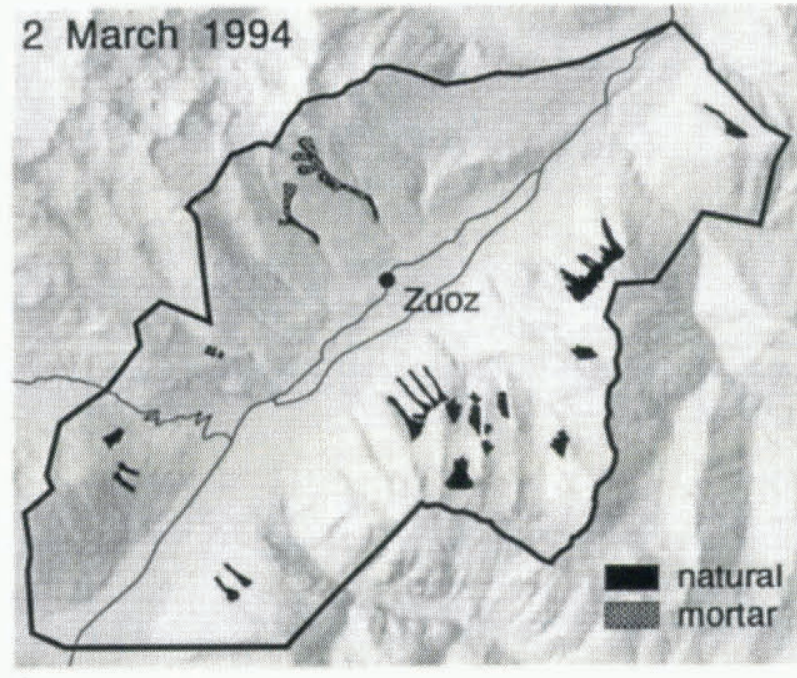

d

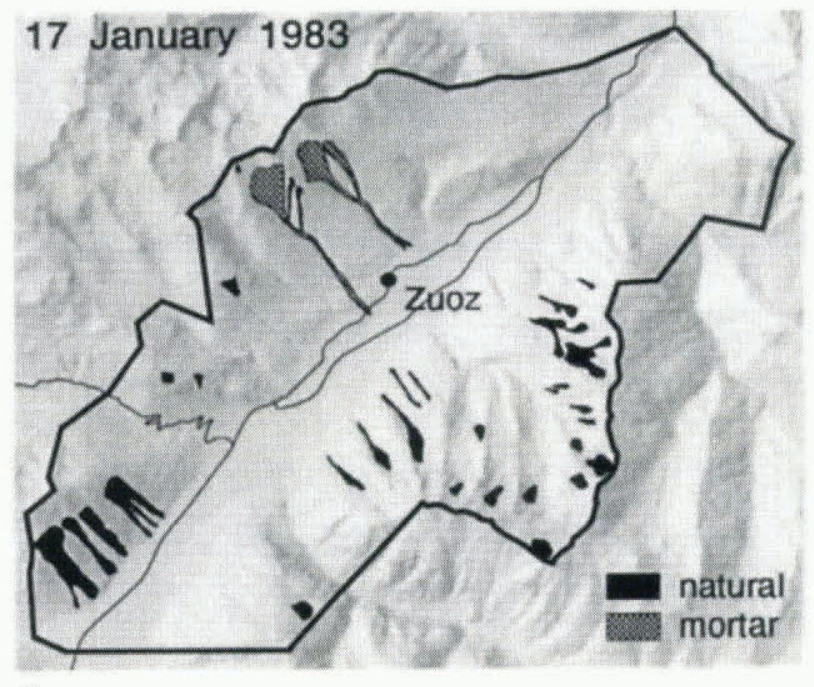

f

Fig. 8. Spatial distribution of avalanche activity for the avalanche situations A-F (Fig. 6; Table 5). Digital map and topographic

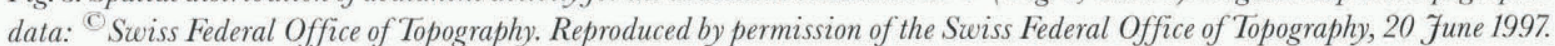


|

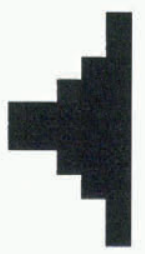

3

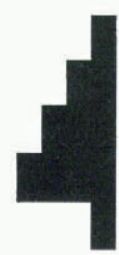

4

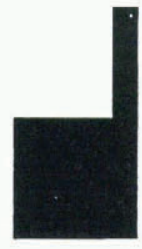

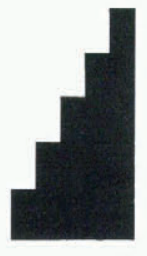

6

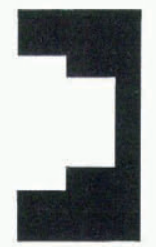

7

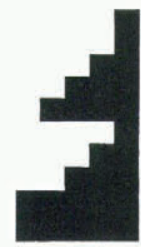

8
Fig. 9. Classification of ram profiles into eight basic types.

to $\left.-1^{\circ} \mathrm{C}\right) .2$ weeks later, air temperature increased more significantly from $-13^{\circ} \mathrm{C}$ at the beginning to $-2^{\circ} \mathrm{C}$ at the end of the snowfall period; in addition, strong southeasterly winds prevailed. Accordingly, the avalanche activity concentrated on the northerly slopes south of the valley. The larger extent of the second situation is also due to the generally larger snow depth. Since the snow-cover stability was rather poor, type of ram profile No. 1 (Fig. 9), avalanches wiped out parts of the old snow, resulting in the release of large masses of snow.

On 26 February 1989 (situation C in Figures 6 and 8) only two medium avalanches were observed, in spite of 45 cm of new snow within 2 days. The winter 1988-89 was poor in snow but with well-consolidated basal layers. On sunny slopes up to $2500 \mathrm{~m}$ a.s.l., there was no snow at all. Accordingly, avalanche activity was very minor. On 2 March 1994, 23 large avalanches resulted from the same amount of new snow (situation D in Figures 6 and 8). The beginning of the winter 1993-94 was characterized by frequent snowfalls $(250 \mathrm{~cm}$ of new snow sum in December and January). During clear and cold weather, through most of February, the surface layers turned into faceted layers and surface hoar developed. During the snowfall period the temperature increased rather significantly destabilizing the new snow that triggered the low-cohesion layers below. The main differences between situations $\mathrm{C}$ and $\mathrm{D}$ are the quantity and the quality of the snow cover.

The mean return period of $80 \mathrm{~cm}$ of new snow within 3 days as found on 23 December 1991 (situation E in Figures 6 and 8) and on 17 January 1983 (situation F in Figures 6 and 8) is about 20 years. On 23 December 1991, 20 medium-sized avalanches with rather short run-out distances occurred mostly on slopes of northern aspect, released on faceted surface layers. The snowfall intensity was high $60 \mathrm{~cm}$ in 24 hours) but temperature was also relatively high, resulting in good bonding to the old snow surface and quick settlement in the course of the snowfall. Situation F on 17 January 1983 was widespread in the Swiss Alps. Several of the 16 large avalanches reached the valley floor. In the two main avalanche paths north of the village, very large avalanches had been triggered causing property damage. Avalanches released on all aspects. Air temperature significantly increased during the snowfall. The old snow cover was weak due to temperature- gradient metamorphism. Depth-hoar layers had developed in particular on northern slopes. Comparing situations E and $\mathrm{F}$ shows that, even for extraordinary amounts of new snow, avalanche activity strongly depends on additional factors such as air-temperature evolution during snowfall and snow-cover conditions prior to snowfall.

\section{CONCLUSIONS AND OUTLOOK}

Based on detailed mapping of avalanche activity by the local snow and avalanche observer at Zuoz, the spatial characteristics of daily-avalanche activity was analyzed using a GIS. This approach has the advantage that avalanche activity can easily be related to terrain characteristics such as elevation, slope angle and aspect. During the 14 year observation period, half of the potential starting zone avalanched at least once. In about half of the major avalanche paths, avalanches were observed once a year. Very large and large avalanche activity each occurs about once each winter, medium activity is seen on 2-3 days per winter. Avalanche activity, avalanche size and avalanche area strongly decrease with increasing frequency of occurrence following a relation that can be described by an exponential function with negative exponent. This feature also holds for the degree of avalanche hazard and seems to be typical of natural hazards (e.g. earthquakes), in general.

The preliminary analysis of the relation between snow data and avalanche activity showed that, even for large amounts of new snow, the new-snow depth is not sufficient to explain the extent of avalanche activity. Large activity can even be seen on days between snowfall periods. However, small activity is more likely for small amounts $<50$ $\mathrm{cm}$ ) of the 3 day sum of new-snow depth and vice versa for large amounts $(>50 \mathrm{~cm})$. But still in half the cases with relatively large amounts $(50 \mathrm{~cm})$ of the 3 day sum of new-snow depth no avalanches (or only small ones) occur. Analyzing some cases showed that the temperature evolution during, and the snow-cover conditions prior to, the snowfall seem to be most decisive. A significant increase (of about $10^{\circ} \mathrm{C}$ ) in air temperature favors the destabilization of new snow. Quantity and quality of the snow cover strongly influence the avalanche size (and volume) and consequently the runout distance. Future knowledge-based systems should reflect this fact, i.e. in particular the quality of the snow cover should be included as an input variable.

Thanks to the detailed mapping the degree of avalanche hazard could be visualized, number, size and location of avalanches can be seen which is highly instructive. This is in particular of importance since the European hazard scale is not used consistently.

The dataset will be further explored to develop a local avalanche-forecasting tool for Zuoz that should help improve the use of avalanche control. The GIS system linking weather, snow and snow-cover data with spatial avalanche activity will be an excellent tool for the future decision-support system, since it is much more indicative of the possible number, size and location of avalanches as output than the result: "avalanches yes or no". The data may also be used to determine frequency run-out relations for specific paths. Finally, the visualization of past avalanche activity will improve models that describe the avalanche-hazard based on terrain characteristics. 


\section{ACKNOWLEDGEMENTS}

This study would not have been possible without the fabulous observations by the local observer A. Möckli from Zuoz. Thanks are due to U. Gätzi who digitized the avalanche areas.

\section{REFERENCES}

De Quervain, M. and R. Meister. 1987. 50 years of snow profiles on the Weissfluhjoch and relations to the surrounding avalanche activity (1936/37-1985/86). International Association of Hydrological Sciences Publication 162 (Symposium at Davos 1986 - Avalanche Formation, Movement and Effects), 161-181.

Föhn, P. 1975. Statistische Aspekte bei Lawinenereignissen. In International Symposium Interpraevent -Schutzalpiner Lebensräume, 1975, Innsbruck, Austria. Vol. 1, 293-304.

Föhn, P. and R. Meister. 1982. Determination of avalanche magnitude and frequency by direct observations and/or with aid of indirect snowcover data. Mitt. Forstl. Bundes-Versuchsanst. Wien 144, 207-228.
McClung, D. M. and P. A. Schaerer. 1993. The avalanche handbook. Seattle, WA, The Mountaineers.

McClung, D. M. and J. Tweedy. 1993. Characteristics of avalanching: Kootenay Pass, British Columbia, Canada. 7. Glaciol., 39(132), 316-322.

Meister, R. 1994. Country-wide avalanche warning in Switzerland. In ISSW'94. International Snow Science Workshop, 30 October-3 November 1994, Snowbird, Utah. Proceedings. Snowbird, UT, P.O. Box 49, 58-71.

Schaer, M. 1995. Avalanche activity during major avalanche events, a case study for hydroelectric reservoirs. In Sivardière, F., ed. Les apports de la recherche scientifique à la sécurité neige, glace et avalanche. Actes de Colloque, Chamonix 30 mai-3 juin 1995. Grenoble, Association Nationale pour l'Étude de la Neige et des Avalanches (ANENA), 133-138.

Schneebeli, M., M. Laternser, P. Föhn and W. Ammann. 1997. Wechselwirkungen zwischen Klima, Lawinen und technischen Massnahmen. Zürich, Hochschulverlag ETH Zürich (vdf). (National Research Program 31. Final report.)

Schweizer, J. and P. M. B. Föhn. 1996. Avalanche forecasting - an expert system approach. f. Glaciol., 42(141), 318-332.

Schweizer, M. 1995. Wissensanalyse und -erhebung mit Kohonen-Netzen am praktischen Beispiel der Lawinenprognose. (Ph.D. thesis, University of Zürich.) 